\title{
Street Men, Family Men: \\ Race and Men's Extended Family Integration
}

Natalia Sarkisian, Boston College

\begin{abstract}
Disorganization theories postulate that black men have largely abandoned their familial roles. Using the NSFH data, this article refutes the hypothesis of black men's familial disengagement by focusing on extended family integration. Black men are more likely than white men to live with or near extended kin, as well as to frequently see kin in person. Men are similar across race in terms of emotional and practical help, although black men are less likely than white men to provide financial assistance. The racial differences can be mostly attributed to the socioeconomic disadvantage of black men. The similarities emerge because blacks' economic disadvantage hinders their involvement, but cultural values and extended family structure bring their involvement to the levels of the more economically advantaged whites.
\end{abstract}

\section{Introduction}

The debate over whether black families are better or worse organized than white families has a long history (Allen 1979; Sarkisian and Gerstel 2004). Scholars on one side of this debate, "superorganization" theorists, argue that blacks have more abundant family ties, and therefore greater family integration, than whites (Allen 1979; Aschenbrenner 1975; Newman 1999; Nobles 1978; Stack 1974; Staples 1981; Sudarkasa 1988). They focus on what they see as positive aspects of black family organization, including strong mother-child relationships, communal patterns of childcare, extended and fictive kin ties, and extensive exchange of support within kin networks. On the other side of this debate, "disorganization" theorists suggest that even though thriving family networks among blacks might have existed in the past, economic and social changes destroyed them, leaving blacks with fewer family ties than Whites (Anderson 1990; Patterson 1998; Roschelle 1997; Wilson 1987).

Disorganization theorists particularly stress the lack of men's presence and involvement in black families. They argue that, compared to white

The author gratefully acknowledges the helpful advice of Naomi Gerstel, Dan Clawson, Joya Misra, Sanjiv Gupta, Nancy Folbre and Sarah Babb. The research was funded in part by a Social Science Research Council Dissertation Fellowship. Direct correspondence to Natalia Sarkisian, Department of Sociology, Boston College, 140 Commonwealth Ave., Chestnut Hill, MA 02453, Phone: (617) 552-0495. E-mail: natalia@sarkisian.net. 
men, black men have in many ways abandoned their familial roles. They attribute this pattern of disengagement either to "dysfunctional" cultural patterns or to social marginalization as a result of concentrated poverty. These scholars usually focus on nuclear family structure, emphasizing "absent black fathers" and mother-headed families as a sign of disorganization (Wilson 1987). Some of them, however, also address the issue of extended kin integration. Focusing on social support among extended kin, these scholars stress the familial disengagement of black men and the substitution of street-corner networks for familial ones (Anderson 1990; Scott and Black 1999).

In contrast, superorganization scholars usually focus on women's family integration, emphasizing woman-centered family and community ties. They frequently leave men's roles in familial networks out of the discussion or emphasize that black women, rather than men, are located in the center of kin networks (Stack 1974; Staples 1981). Some superorganization proponents, however, stress black men's role as "other fathers" - family members or community members who are deeply involved in parenting children other than their own (Lempert 1999; Whitmore 1999). Superorganization scholars also argue that black men may be contributing to multiple households simultaneously (e.g., those of their mother, an ex-wife, and a girlfriend raising their children); they can also be active in multiple matrifocal extended families (Aschenbrenner 1975). In other words, these theorists argue that rather than being disengaged from family life, black men are actually involved with several families (Johnson 1999). Despite this acknowledgement, however, the research from the superorganization perspective pays little attention to men's familial roles in general (Lempert 1999) and their extended family involvement in particular.

Extended family ties, however, are regaining prominence as a subject of sociological inquiry. Scholars who focus on minority families are particularly likely to emphasize the importance of broad family ties. They stress the racial bias inherent in an analytic focus on nuclear families and argue for the need to develop models that move beyond the ethnocentric nuclear family model (Collins 2000; Gerstel and Sarkisian, forthcoming). In line with such arguments, this research addresses the lack of both theoretical discussion and empirical research on black men's extended family integration.

Using the second wave of the National Survey of Families and Households (NSFH), it tests hypotheses concerning black men's familial disengagement by comparing their extended family integration to that of white men. Extended family integration is conceptualized as a multidimensional construct, including two major components: 1.) 
physical proximity of kin, including coresidence and living nearby, and 2.) involvement with kin, including contact and kin support. The twopart empirical analysis assesses the assumptions of the disorganizationsuperorganization debate by 1.) evaluating the differences and similarities between white and black men's extended family integration and 2.) explaining the racial differences and similarities in extended family integration using socioeconomic characteristics, cultural values and family composition.

\section{Black Men's Extended Family Integration: Research on Race Differences and Similarities}

In their extensive review of the literature on black families, Taylor and his colleagues (1990) concluded that one of the most conspicuous gaps in this literature was the lack of studies on the family life of black men. More than 15 years later, this gap still persists. The research on black men's participation in nuclear families finds that compared to white men, black men are less likely to be married and more likely to be nonresident fathers (Taylor et al. 1997; Tucker and Mitchell-Kernan 1995). In terms of extended family integration, however, limited evidence exists to substantiate the claims of either disorganization or superorganization theorists.

Many studies combine women and men when examining racial differences in extended family involvement (for a review, see Sarkisian and Gerstel 2004). This is problematic, because research has clearly demonstrated that black men are somewhat less involved with extended families than black women (Spitze and Miner 1992; Laditka and Laditka 2001; Roschelle 1997; Silverstein and Waite 1993. Studies that focus specifically on men are scarce, however.

Examining coresidence, scholars found that black men are more likely than white men to share a residence with extended kin (Coward et al. 1996; Goldscheider and Bures 2003; Raley 1995). Looking at contact, Raley (1995) found that compared to white men, black men have more frequent contact with their mothers and less frequent contact with their siblings; she also found that overall, black men socialize with relatives more often than white men. Further, a few studies compared black and white men's involvement in giving kin support, but the findings were mixed. Raley (1995) used a measure of kin support combining two types of practical support and one type of emotional support, and found black and white men equally likely to give support to kin. In contrast, Roschelle (1997) found that black men were less likely than white men to help kin with household tasks. Similarly, Laditka and Laditka (2001) found that black men were less likely to give practical help to parents; nevertheless, 
among those men who gave help, black men provided significantly more hours than white men. Finally, Silverstein and Waite (1993) found that compared to white men, black men were less involved in practical and emotional support transfers with parents and adult children, but somewhat more involved in such transfers with siblings and other relatives. Thus, the variation in the findings on kin support can be probably attributed to differences in the types of kin support analyzed, the types of kin included in the analyses (e.g., parents, adult children, siblings, etc.), as well as the methodologies used (e.g., type of sample, definitions of variables, use of controls, methods of analysis).

\section{Theorizing the Race Differences and Similarities in Men's Extended Family Integration}

Superorganization and disorganization theorists propose a number of explanations for what they consider to be the unique patterns of black family organization. Importantly, these explanatory frameworks focus exclusively on the factors that shape racial differences. Little theorizing and no research addresses the factors that create racial similarities in extended family integration. Like much sociological research, those studies that find similarities often brush them aside, seeking only to report and explain statistically significant differences (Epstein 1988). I argue instead that it is important to theorize models that could produce racial similarities. Two such models can be identified. The first one, the irrelevance model, suggests that those factors that distinguish blacks and whites are inconsequential for extended family integration. The second model, termed the paradox model, suggests that these factors shape familial integration, but some of them lead to higher levels of integration among blacks while others lead to more integration among whites. Together these factors push the race differential in opposite directions, producing the observed similarities. Given the absence of literature on similarities, to pinpoint the factors that should be considered when empirically evaluating these two pathways, this research relies on the literature that explores the factors shaping race differences. The explanatory factors identified in this literature can be broadly divided into cultural and structural.

\section{Cultural Explanations}

Some theorists from both the disorganization and superorganization perspectives have argued that cultural values are crucial to understanding the race differences in family integration. On the one hand, this includes cultural deficiency theorists who attribute black family disorganization to 
deviant cultural values among blacks, especially the absence of cultural norms promoting marriage, tolerance for non-marital childbearing, preference for so-called "matriarchy" (typically implying that "strong" black women prefer to be family heads and thus push men away), and general mistrust and cynicism (Frazier 1939; Moynihan 1965; Patterson 1998; Wilson and Musick 1997). On the other hand, cultural explanations are also utilized by the cultural resiliency theorists. Some of them attribute black family patterns to the preservation of traditional African cultures and continuing preferences for family organization forms found in these cultures, manifested through extended familistic values and a high value placed on childrearing, as well as the matrilateral focus placing women rather than men in the center of family functioning (Aschenbrenner 1975; Johnson 2000; Nobles 1978; Staples 1981; Sudarkasa 1988). Other cultural resiliency theorists focus on the cultural outcomes of slavery and oppression, and argue that the common experience of oppression generated integration-boosting ethnic solidarity, altruism (Carson 1989), and religiosity (Littlejohn-Blake and Darling 1993).

Studies have found higher levels of extended familism among blacks than among whites (Burr and Mutchler 1999; Gaines et al. 1997). There is also some evidence of higher levels of altruistic and collectivistic values (Allen and Bagozzi 2001; Gaines et al. 1997; Johnson, Matre and Armbrecht 1991) and higher levels of religiosity and church attendance among blacks than whites (Johnson, Matre and Armbrecht 1991; Krause 2002; Taylor et al. 1996). Further, some studies also supported the assertion that blacks are more child-centered (Hoffman and Manis 1979; Jacobsen and Binger 1991; Thompson 1980). Much research also has demonstrated that blacks place lower value on marriage and are more accepting of nonmarital childbearing than whites (Moore and Stief 1991; Oropesa and Gorman 2000; South and Baumer 2000), although some found stronger pro-marriage beliefs among blacks than whites (Tucker 2000).

Unfortunately, the actual effects of these cultural factors on extended family integration are rarely examined. Those few studies that attempt to assess the impact of culture on kin involvement focus on extended familistic values; they do not consider the entire range of cultural values theorized to influence family integration. They examine values such as "respect for young" and "respect for old" (Mutran 1985) or "familism" (Roschelle 1997) and find no effect or a limited positive effect of such values on kin support involvement. Overall, however, cultural explanations are usually used only as a residual category: Those race differences that remain after controlling for socioeconomic variables and family composition are typically interpreted as a product of cultural differences. 


\section{Structural Explanations}

As is the case with cultural explanations, both disorganization and superorganization approaches also have relied on structural factors, and more specifically, socioeconomic standing characteristics, to explain race differences in family integration. Structural destruction theorists (McDonald and Armstrong 2001; Roschelle 1997; Wilson 1987) and structural resiliency theorists (Allen 1979; Lempert 1999; Newman, 1999; Stack 1974) alike argue that the differences between black and white families result from the different contemporary structural positions of these two groups, emphasizing disparities in education, employment, income and wealth. Structural destruction theorists argue that the lack of resources leads to lower levels of familial involvement (Roschelle 1997), and attribute the black men's familial disengagement to their persistent poverty and joblessness (Wilson 1987), as well as the associated problems such as drugs, crime and high incarceration rates (Anderson 1990). Structural resiliency theorists, in contrast, argue that blacks' higher levels of extended family integration are due to the fact that poor families need to maintain higher levels of integration in order to make ends meet.

Most studies of race differences in extended family integration include some measures of socioeconomic standing, usually income and education, and sometimes employment. The findings differ substantially across studies: Some studies find that higher socioeconomic standing (measured by income and education) increases the likelihood of kin integration for whites and blacks (Cooney and Uhlenberg 1992; Eggebeen 1992; Hatch 1991; Hogan, Eggebeen and Clogg 1993; Roschelle 1997; Silverstein and Waite 1993), while others find decreased extended family integration at higher socioeconomic standing levels (Laditka and Laditka 2001; Mutran 1985). Some studies even report that education and income operate in opposite directions (Jayakody 1998). Some scholars account for employment status as well, finding either that those employed have higher levels of kin involvement (Silverstein and Waite 1993), or that they are no different from those not employed (Cooney and Uhlenberg 1992; Hatch 1991; Roschelle 1997). It is possible that these differences can be attributed to the variation in the measures of kin integration or in the types of kin included in these analyses. Furthermore, in most of these studies, the socioeconomic standing variables are used with an assortment of controls that can serve as mediators, but the role of these variables is not acknowledged.

\section{Family Composition Factors}

Although culture and structure are the two main explanations used to account for the race differences in family organization, scholars also 
recognize that nuclear and extended family composition may shape extended kin integration. Because the racial differences in family composition are themselves a subject of the same culture vs. structure debate, however, it can be argued that family composition variables can indirectly represent both cultural and structural influences and operate as mediating variables.

Studies of race differences in kin ties often control for some aspects of nuclear family structure, including marital status and the presence of children, as well as for extended kin composition. Furthermore, studies of kin contact and kin support often include measures of kin coresidence and proximity as controls. In the case of extended family composition, there is agreement regarding its effects on kin integration. Specifically, having more relatives increases the chances of living near them, seeing them and helping out (Roschelle 1997). Similar conclusions have been reached regarding the effects of physical proximity to kin. Both coresidence and living near kin increase extended family involvement (Eggebeen 1992; Hogan et al. 1993).

In contrast, there is much confusion regarding the effects of nuclear family composition. Black men are less likely to have spouses or partners and are more likely to be nonresident fathers; blacks also have more children on average than whites (Taylor et al. 1997; Tucker and Mitchell-Kernan 1995). Scholars, however, disagree on the effects of these differences. Some insist that having a spouse or a partner increases the size of an individual's familial network and promotes closeness to kin, providing more opportunities for kin integration (Fischer et al. 1989), and that divorce decreases such networks (Wallerstein and Kelly 1980). Others, however, argue that marriage is a "greedy institution" taking away time and resources that might otherwise be spent on visiting or helping extended kin (Gerstel and Sarkisian 2006; Sarkisian and Gerstel, forthcoming). A similar debate contests the effects of children on kin support. Whereas some maintain that children consume parents' time and resources, reducing their availability for kin involvement (Moore 1990), others argue that children increase the need for support and connect individuals to others, especially extended kin (Ambert 1992; Gallagher and Gerstel 2001).

\section{Contributions of This Study}

The research on black men's extended family integration is scarce. Theoretical disagreements about family integration among black men are intensified by 1.) a lack of studies using national data to examine both the racial differences and the racial similarities in extended family integration, 2.) the tendency of many kinship studies to combine women and men, 3.) the tendency to examine one aspect of family integration rather than a 
range of indicators, 4.) the tendency to focus on a single type of kin, and 5.) a lack of systematic evaluation of the role of both cultural and structural factors in shaping racial differences and similarities.

This research aims to fill this gap by comparing the extended family integration of black and white men and explaining both racial differences and similarities. To avoid the limitations of prior literature, it utilizes data from a nationally representative sample of black and white men, examines a range of family integration measures and relies on a broad definition of extended kin. Further, in contrast to much prior research, this article systematically assesses the extent to which culture and structure explain racial differences and similarities in extended family integration by employing regression decomposition.

\section{Data and Variables}

This article utilizes data from the second wave (1992-94) of the National Survey of Families and Households, in which a total of 10,005 main respondents were interviewed. The data were collected from a stratified, multistage area probability U.S. sample, which included an oversampling of blacks (for additional information on the NSFH, see Sweet and Bumpass 1996). This study focuses on a subsample limited to white $(N=2893)$ and black $(N=590)$ men.

\section{Dependent Variables}

The dependent variables are dichotomies covering two main domains of family integration: proximity to kin and involvement with kin. Coresidence variable indicates whether respondents coresided with any extended kin (including parents, adult children ages 19+, siblings and other relatives). Living near kin variable indicates whether the closest non-coresident kin (includes parents, parents-in-law, adult children, and siblings) lived within 2 miles of the respondent. This dichotomy is based on the frequency distribution as well as Roschelle's (1997) categories because the continuous proximity variable was highly skewed with a mean of 116 miles and a median of only 5 miles.

The measure of contact is based on questions that asked respondents how often in the past 12 months there had been any contact in person with each of the following types of relatives not living in the same household: mother, father, mother-in-law, father-in-law, adult children, or grandchildren. Respondents could select never, about once a year, several times a year, one to three times a month, about once a week, or more than once a week. When a respondent did not have any kin in a particular category, 
responses were coded as never to be consistent with other measures of family integration that are also contingent on the availability of kin. To keep the analyses uniform across the measures of family integration and to simplify the presentation of the results, a dichotomous variable was used indicating frequent (at least once a week) contact with at least one type of non-coresident kin.

To examine the full spectrum of kin support, this research utilized measures of each of the three major types identified in the literature (Fischer et al., 1989): emotional, financial and practical. The financial support variable was constructed using questions asking whether the respondent or spouse 1.) gave a gift worth more than $\$ 200$ at any one time in the last 12 months to anyone not living with them at the time, 2.) gave such a loan worth more than $\$ 200 ; 3$.) paid someone's day-to-day living expenses or educational expenses. If involved in any of such transfers, respondents were asked to whom they gave the highest gift amount and the highest loan. (For help paying expenses, the respondent was asked to name only one person to whom the respondent provided such help.) If at least one of these recipients was a relative, the respondent was coded as giving financial support to kin.

The emotional support variable is based on the questions that asked if the respondent gave "advice, encouragement, moral or emotional support" in the last month to the following three groups of relatives residing outside of their household: (a) parents/children; (b) siblings; and (c) other relatives. The emotional support variable was coded as one if the respondent provided this type of support to at least one group of kin.

The practical support variable is based on questions that asked whether respondents gave each of the three types of practical help in the past month to the same three groups of non-coresident kin: parents/ children, siblings, and other relatives. The three types of help specified in these questions included: help with transportation; help with housework, yardwork, car repairs and other work around the house; and help with baby sitting or child care. The practical support variable was coded as one if the respondent provided at least one of these types of help to at least one of the categories of kin.

\section{Independent Variables}

My measure of race is a dichotomous variable, Black, coded as one for respondents who stated that they are black. The omitted category is White, coded as zero for respondents who identified as white, not of Hispanic origin. Five groups of independent variables were used along with race: cultural variables, socioeconomic variables, nuclear family composition, extended family composition and controls. 
Four scales were used to measure cultural values (see Appendix A for the list of survey items). Scale reliability was assessed using Chronbach's alpha; following Nunnally (1978), alphas of .50 and over are considered acceptable. The scales include attitudes on the value of marriage (alpha $=.82$ ), beliefs regarding the importance of having children (alpha $=.80$ ), extended familistic attitudes (alpha $=.62$ ), and altruistic attitudes (alpha $=.50)$. Respondent's religious involvement was measured using a church attendance variable indicating whether the respondent attended religious services at least once a year.

Socioeconomic status is represented by six measures: income, wealth, education, employment hours, car ownership and home ownership. Income was operationalized as the total household income per person (income of all household members divided by the household size) in the past year, measured in $\$ 10,000$ s. Income per capita was used because such a measure reflects the socioeconomic standing of the entire household. This variable was top coded income at $\$ 100,000$ and used the square root to improve its distributional properties. The wealth variable was calculated as total assets minus total debts of respondent and spouse or partner measured in $\$ 10,000$ s and divided by two if a spouse/partner is present. It is truncated based on the variable's distribution, on the bottom at negative $\$ 15,000$ (debts) and on the top at positive $\$ 500,000$ (assets), and includes the value of and debt on home, other real estate, vehicle, and business or farm, total value of savings and investments, and total amount owed on credit cards, installment loans, educational loans, bank loans or mortgage, loans from friends or relatives, home improvement loans, other bills outstanding for more than two months, and other debts.

The education variable indicated the number of years of completed education. The hours of employment variable indicated the number of hours typically worked per week. It was based on the hours worked during the preceding week on the main job if that was a typical week for the respondent, or on the number of hours worked in a typical week if the preceding week was not typical. Finally, the vehicle ownership variable indicates if the respondent or his spouse own motor vehicles, including cars, trucks, campers, boats, and other recreational vehicles, and the home ownership variable indicates if the respondent or his spouse own or are buying their home.

Three variables are used to describe nuclear family composition. Unpartnered variable measuring the relationship status indicates whether the respondent was not married and not cohabiting. Another dichotomy indicates whether the respondent had his own or a spouse/ partner's minor children (biological, adopted or foster) residing in the household. Finally, the third dichotomy indicates whether the respondent 
is a nonresident father, that is, has minor children (biological, adopted or foster) residing elsewhere.

To describe extended family composition, four variables are used. The presence of adult children variable indicates whether the respondent had any children (biological, adopted or foster) older than 18 years residing in or out of the household. The grandchildren variable indicates whether the respondent had grandchildren - that is, whether respondent's children or spouse/partner's children had children (or stepchildren). The living parents variable indicates whether at least one of the respondent's own parents was still living. The number of siblings variable reflects the total number of respondent's siblings (full siblings, half-siblings and stepsiblings) truncated at 10 to improve the distribution and reduce the impact of outliers.

Finally, controls include measures of age and health. Age is measured in full years. The health variable is a scale (Cronbach's alpha $=.61$ ) based on three sets of questions: 1.) Compared with other people your age, how would you describe your health on a scale of 1 (very poor) to 5 (excellent)? 2.) How satisfied are you with your health according to a scale of 1 (very dissatisfied) to 7 (very satisfied)? 3.) "How much do physical or mental conditions limit your ability to ...." do seven different everyday tasks assessed by a question for each on a scale from 1 (doesn't limit at all) to 3 (limits a lot).

\section{Analytic Strategy}

The analysis consists of two parts. The first part entails bivariate analyses that assess the differences and similarities between black and white men in family integration measures and in the independent variables. For each of the variables, weighted means were calculated separately for black and white men, followed by significance tests for the differences between racial groups. The second part entailed two sets of multivariate analyses: 1.) a set of logistic regression models to assess whether culture, structure, family composition and control variables jointly explained the differences between blacks' and whites' extended family integration; and 2.) a set of regression decomposition analyses to identify the relative contribution of culture, structure, family composition and controls to explaining racial differences and similarities

The set of logistic regression models contained two types: first, those including the race variable only, and second, those including the full set of predictors - cultural, socioeconomic, nuclear family, extended family and controls. In line with prior research on kin contact and support that showed that proximity shapes involvement, the models for these 
outcomes include coresidence and living nearby within the extended family variables set.

The changes in the race variable coefficients from the first to the second type of model show whether the predictors account for the racial differences in integration. To assess the specific contribution of each predictor to explaining racial differences, regression decomposition technique is used to calculate compositional effects: the effects of the group differences in the means of predictors on the group difference in the dependent variable. For logistic regression, compositional effects are calculated as $1 / 2\left(b_{\text {White }}+b_{\text {Black }}\right)\left(\bar{x}_{\text {White }}-\bar{x}_{\text {Black }}\right) p(1-p)$, where $\bar{x}_{\text {White }}$ and $\bar{x}_{\text {Black }}$ represent the means of an independent variable, $b_{\text {White }}$ and $b_{\text {Black }}$ represent the coefficients for that variable from separate logit models for blacks and whites, and $p=1 / 2\left(p_{\text {Black }}+p_{\text {White }}\right)$ is the proportion for the family integration measure (see Glick, Bean and Van Hook, 1997, for more details on this technique). Compositional effects allow an assessment of whether (and which) cultural and structural differences account for racial differences in integration. Logistic regression coefficients are used to assist in the interpretation of compositional effects. Further, although regression decomposition technique historically has been used to explore differences, I extend it to understanding similarities. Specifically, regression decomposition analysis examines how race differences in cultural, socioeconomic and family composition characteristics produce similar levels of integration. This allows testing of the irrelevance and the paradox models.

To obtain generalizable results, all of the analyses used analytic weights adjusting for oversampling, nonresponse, and attrition, as well as aligning selected demographic characteristics of the sample to those in the population. These analyses also utilized standard error estimates adjusted for the clustered and stratified nature of the sample.

\section{Results}

The analysis begins with racial comparisons of men's kin integration. The top portion of Table 1 shows that black men are much more likely than white men to live with or near kin. In fact, combining these two measures, we find that 71 percent of black men, but only 48 percent of white men live with or near extended kin. Next, Table 1 shows that black men (75.7 percent) are much more likely than white men (59.4 percent) to have frequent face-to-face contact with their kin. Further, although whites are more likely than blacks to be involved in giving financial support, blacks and whites do not differ in their rates of emotional support and practical help. Furthermore, if the three types of support are combined, the overall 
Table 1: Variable Means by Race

\begin{tabular}{|c|c|c|}
\hline Variables & $\begin{array}{l}\text { Whites } \\
\text { (N=2983) }\end{array}$ & $\begin{array}{c}\text { Blacks } \\
(\mathrm{N}=590)\end{array}$ \\
\hline \multicolumn{3}{|l|}{ Proximity to Kin: } \\
\hline $\begin{array}{l}\text { Coresidence } \\
\text { Living nearby }\end{array}$ & $\begin{array}{l}19.15 \\
35.62\end{array}$ & $\begin{array}{l}43.55^{\star \star \star *} \\
50.29^{\star \star \star}\end{array}$ \\
\hline \multicolumn{3}{|l|}{ Involvement with Kin: } \\
\hline Frequent contact & 59.40 & $75.70^{\star \star *}$ \\
\hline Financial assistance & 32.27 & $23.76^{* * *}$ \\
\hline Emotional support & 65.60 & 63.67 \\
\hline Practical help & 60.10 & 61.80 \\
\hline \multicolumn{3}{|l|}{ Culture: } \\
\hline Value of marriage & .06 & $-.11^{* \star *}$ \\
\hline Value of children & .10 & .06 \\
\hline Extended familism & .02 & $.20^{\star \star \star}$ \\
\hline Altruism & -.14 & $.04^{* \star *}$ \\
\hline Church attendance & .70 & $.82^{\star \star *}$ \\
\hline \multicolumn{3}{|l|}{ Socioeconomic Status: } \\
\hline Income per person (square root) & 1.37 & $1.04^{\star \star \star}$ \\
\hline Wealth & 7.53 & $2.42^{\star \star \star}$ \\
\hline Education & 13.44 & $11.53^{\star \star \star}$ \\
\hline Employment hours & 31.56 & $28.44^{\star}$ \\
\hline Vehicle ownership & .93 & $.77^{* \star *}$ \\
\hline Home ownership & .72 & $.48^{\star \star \star}$ \\
\hline \multicolumn{3}{|l|}{ Nuclear Family Composition: } \\
\hline Unpartnered & .22 & $.42^{\star \star \star}$ \\
\hline Minor children in household & .35 & .34 \\
\hline Nonresident father & .10 & $.23^{\star \star \star}$ \\
\hline \multicolumn{3}{|l|}{ Extended Family Composition: } \\
\hline Living parents & .67 & .67 \\
\hline Number of siblings (log) & 1.20 & $1.55^{\star \star \star}$ \\
\hline Adult children & .48 & .47 \\
\hline Grandchildren & .34 & .37 \\
\hline \multicolumn{3}{|l|}{ Controls: } \\
\hline Age & 47.62 & $44.55^{\star \star \star}$ \\
\hline Health & .08 & .05 \\
\hline
\end{tabular}

Note: Statistically significant differences are indicated as follows:

${ }^{*} p<.05 \quad{ }^{* *} p<.01 \quad{ }^{* * *} p<.001$ (two-tailed tests). 
rates of support are similar for blacks and whites: 82.3 percent of black men and 82.6 percent of white men provide at least one type of support. That is, only about 18 percent in each group are not at all involved in helping extended kin.

Table 1 also examines race differences for a variety of explanatory variables. Black and white men differ on most measures of cultural values. On average, black men place less value on marriage, express more familistic and altruistic attitudes, and attend religious services more often than white men. Similarly, there are many differences between blacks and whites on structural measures: Black men have significantly lower incomes, less wealth and less education, and they work for pay fewer hours than white men. Not surprisingly, black men are also less likely than white men to own cars and houses. There are also some differences in terms of the nuclear and extended family composition. Black men are more likely than white men to be unpartnered and to be nonresident fathers, although the two groups are equally likely to have minor children in the household. On average, black men have more siblings than white men, but the two groups are equally likely to have adult children, grandchildren or living parents. Finally, black men are younger on average than white men, but they do not differ in their health ratings.

Next, this research turns to multivariate analyses that assess the extent to which these ethnic differences in culture, socioeconomic status, family structure and controls help explain racial differences and similarities in proximity to kin and extended family involvement. Table 2 focuses on proximity to kin and presents the results of logistic regression and regression decomposition analyses attempting to explain racial differences in proximity. The first two rows of coefficients present odds ratios for the race variable from two logit models: the race only model and the full model containing indicators of culture, socioeconomic status, family structure, and controls. By examining the changes in the race odds ratios from the race only model to the full model, we can determine whether the predictors accounted for the racial differences in proximity to $\mathrm{kin}$. Because an odds ratio of 1.0 indicates no effect, the closer an odds ratio is to 1.0 , the smaller the effect of the corresponding variable.

The subsequent rows present odds ratios and compositional effects for each of the predictors. The compositional effects assess each predictor's contribution to explaining the race difference in proximity to kin, while the odds ratios indicate how each predictor shapes proximity to kin. Therefore, odds ratios can assist in the interpretation of compositional effects. The compositional effects represent the amounts of black-white differential in living with or near kin that can be attributed to the race differences in means of predictors. A positive number indicates that the corresponding 
Table 2: Explaining Black-White Differences in Proximity to Kin

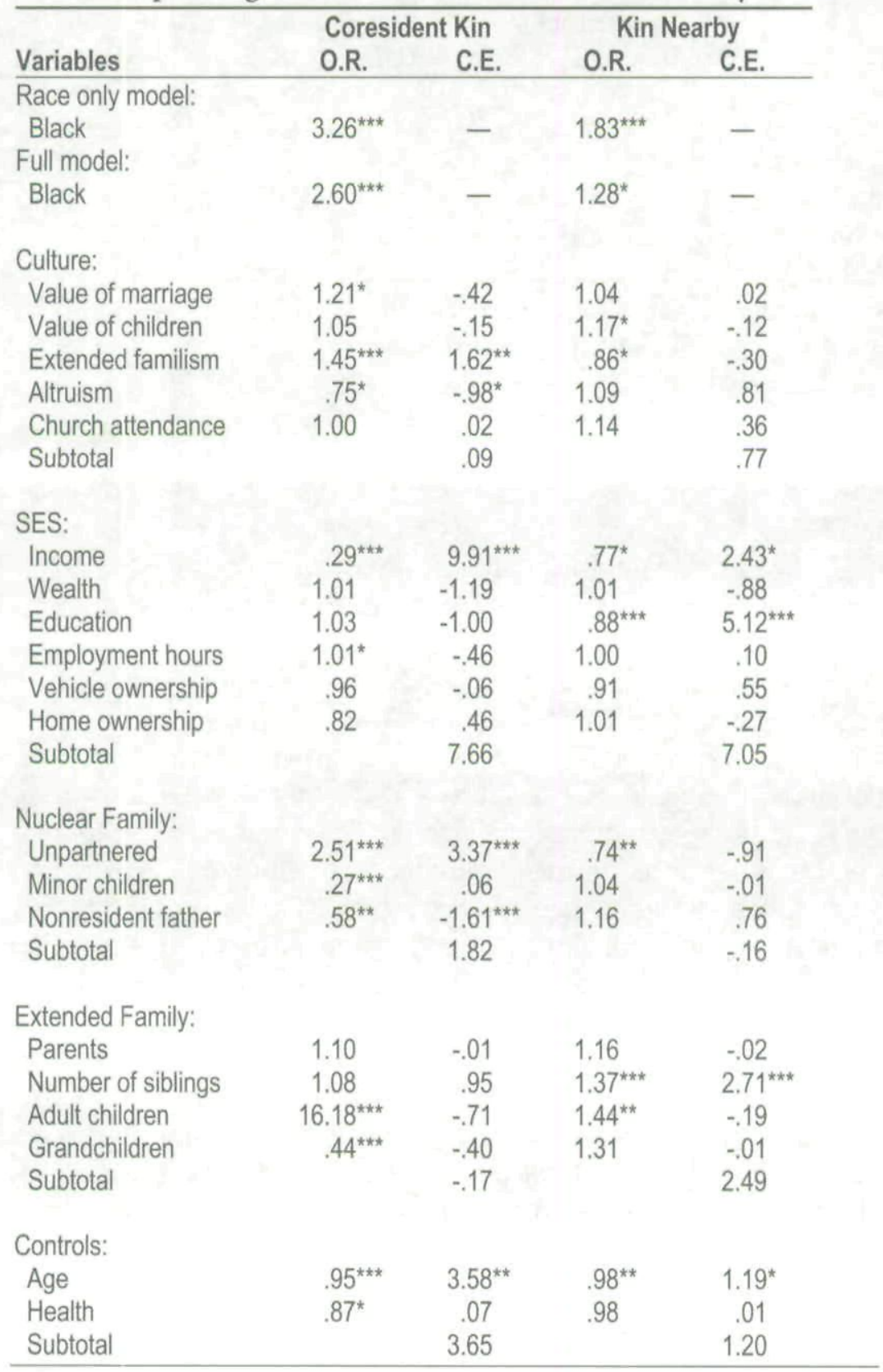


Table 2 continued

\begin{tabular}{|c|c|c|}
\hline & Coresident Kin & Kin Nearby \\
\hline Variables & O.R. C.E. & O.R. C.E. \\
\hline \multicolumn{3}{|l|}{ Summary: } \\
\hline Observed rate black & 43.55 & 50.29 \\
\hline Observed rate white & 19.15 & 35.62 \\
\hline Observed difference & 24.40 & 14.67 \\
\hline Total explained & 13.05 & 11.35 \\
\hline Adjusted difference & 11.35 & 3.32 \\
\hline
\end{tabular}

Note: O.R. = Odds Ratios; C.E. $=$ Compositional Effects.

Statistically significant coefficients are indicated as follows:

${ }^{*} \mathrm{p}<.05 \quad{ }^{* *} \mathrm{p}<.01 \quad{ }^{* * *} \mathrm{p}<.001$ (two-tailed tests).

race difference in means results in a higher rate of proximate living for blacks than for whites and therefore brings about an increase in the blackwhite differential. A negative number indicates that the mean difference results in a higher rate of proximate living for whites than for blacks and therefore brings about a decrease in the black-white differential (which can also be viewed as an increase in the white-black differential).

In addition to the amount of black-white differential explained by each independent variable, Table 2 presents subtotals for each group of variables - cultural, structural, nuclear family composition, extended family characteristics and controls. Each of these subtotals is calculated as the sum of the amounts explained by the variables in that group. Finally, the bottom portion of Table 2 includes the summary of regression decomposition. This includes, first, the observed percentages of proximate living for blacks and whites and the difference between them - the blackwhite race gap. Second, it includes the total explained which is the sum of all subtotals; it represents the total amount of the racial gap that can be attributed to the racial differences in the independent variables used in the model - i.e., the total compositional effect. Finally, the last line of the summary presents the adjusted race difference, calculated by subtracting the total from the observed race difference. This is the difference remaining after accounting for the compositional effects of all the predictors in the model.

The subtotals for the compositional effects are also graphically presented in Figure 1. For each dependent variable, this figure includes six bars. The first bar represents the size of the existing race gap (percentage of black men minus percentage of white men who reported participating in each family integration behavior). The following five bars in each set display the amounts of this black-white gap that can be attributed to the 


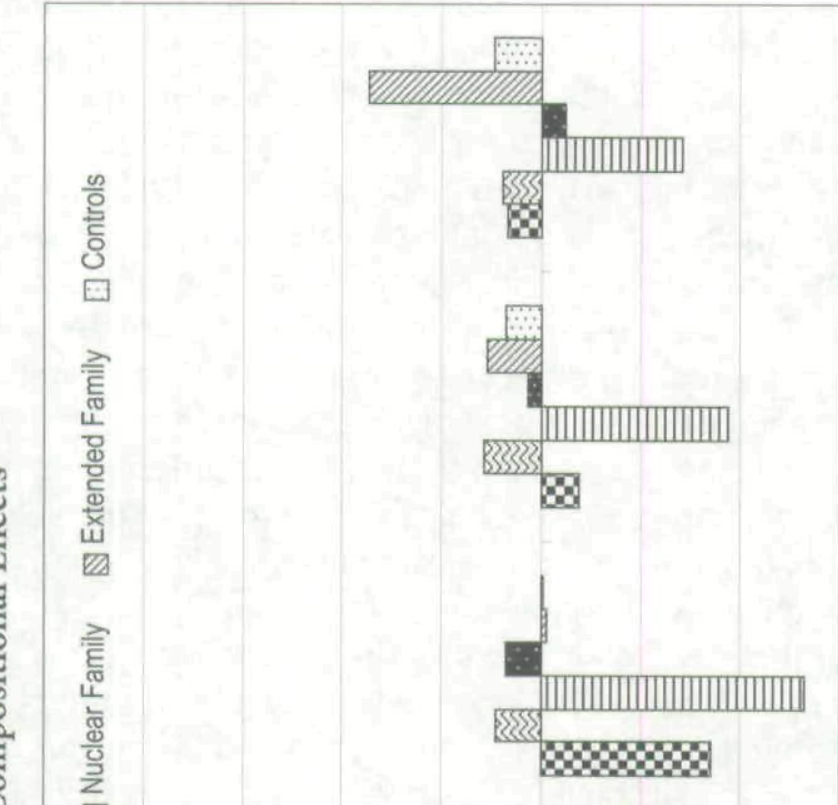

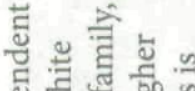

施

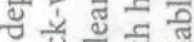

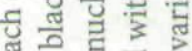

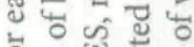

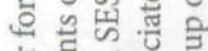

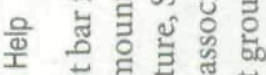

तु

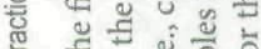

든

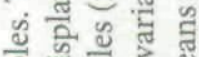

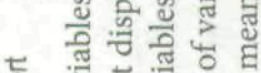

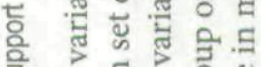

골

त कू ฮี

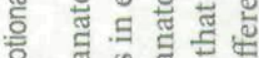

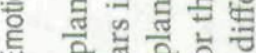

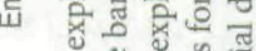

\& पेّ

ट्ञ

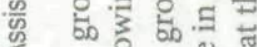

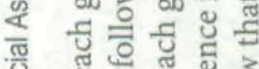

픙

एँ

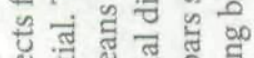

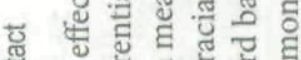

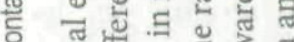

응

च्ञ

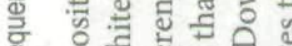

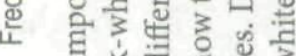

붱

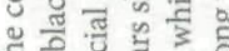

흉

\& $\frac{5}{2}$ 约

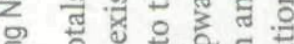

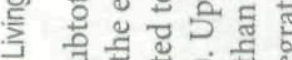
कै 을 을 ษ

\&

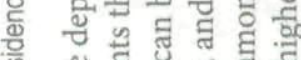

은 릉

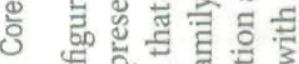

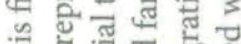
ह

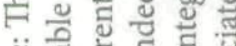

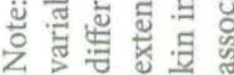


racial differences in means of each group of explanatory variables (i.e., culture, structure, nuclear family, extended family and controls). These bars demonstrate each group's contribution to explaining the gap. Upward bars (representing positive numbers) show that the racial difference in means for that group of variables results in higher family integration among blacks than among whites. Downward bars (representing negative numbers) show that the racial difference in means for that group of variables results in higher kin integration among whites than among blacks. Thus, for racial gaps favoring blacks, upward bars indicate the groups of variables that help explain the existing gap, and downward bars indicate the groups of variables that do not help explain the existing gap: rather, these latter characteristics explain why this gap is smaller than it could have been. For racial gaps favoring whites, however, the reverse is true: Downward bars indicate the groups of variables that help explain the gap, and upward bars point to those groups of variables that keep the gap smaller than it could be. Finally, for those integration measures where no racial gaps were observed, upward bars indicate the groups of variables that create a gap favoring blacks, and downward bars point to the groups of variables that generate a gap favoring whites.

The comparison of the race only models to the full models in Table 2 shows that for both coresidence and living near kin, the joint introduction of culture, structure, family composition, and control variables greatly reduces but does not fully explain racial differences. Thus, even controlling for cultural, socioeconomic and family composition factors, black men are significantly more likely than white men to live with or near extended kin. As the compositional effects indicate, a large chunk of the race gap in coresidence is explained by socioeconomic variables: They account for 7.7 percent of the 24.4 percent gap. Here, it is income that contributes the most: As the odds ratio indicates, those with higher incomes are less likely to coreside with kin. Thus, the lower average income of blacks generates a substantial race gap in coresidence. Controls (and more specifically, respondent's age) explain another 3.6 percent of the gap. Nuclear family composition accounts for another 1.8 percent, although within that category, we can observe two opposite effects: Being single increases chances of coresidence, and being a nonresident father decreases them, but black men are more likely than white men to be in both of those categories. In contrast, culture and extended family composition contribute little to explaining the race gap in coresidence. As the total explained value indicates, this model accounts for more than half of the race gap: 13.1 percent of a 24.4 percent difference.

Forliving nearby, the data show that SES, extended family characteristics, and age explain much of the race difference favoring blacks. Education, 
and to a smaller extent income, account for a substantial portion of the race gap: Higher levels of education and income are linked to a reduction in the likelihood of living near kin. In contrast, cultural variables do not help explain the gap. When taken together, all variables account for 11.35 percent of the 14.67 percent race gap, although the remaining difference is still statistically significant.

Turning to involvement with kin, Table 3 presents the odds ratios and compositional effects foe kin contact and kin support. First, the odds ratios for race show that our model fully explains the race difference in face-to-face contact. Extended family characteristics, especially the rates of coresidence and living near kin, explain a large portion of the gap (11.38 percent of the 16.31 percent gap). The remainder is accounted for by the race differentials in education and age: Black men are younger and less educated on average, and age and education are linked to lower likelihood of frequent contact with relatives.

Next, the race gap in giving financial assistance is also rendered insignificant in the full model. The difference in income and education appear to be the most prominent here, creating a 6.4 percent and 3.6 percent gaps favoring whites, respectively. Combined, the socioeconomic variables generate a 13.2 percent gap which is larger than the 8.5 percent gap that was actually observed. The observed gap is smaller because the race differences in cultural values and nuclear family characteristics partially compensate for the effects of SES: As the subtotals for these groups indicate, they create 2.3 percent and 1.8 percent gaps favoring blacks, respectively. Specifically, it is the higher rates of church attendance as well as higher prevalence of nonresident fatherhood among black men that increase their rates of giving financial assistance. These conflicting influences on the race gap in financial assistance can be clearly seen in Figure 1. Nevertheless, the effects of socioeconomic standing are too large to be fully compensated for by these other factors.

Turning to emotional support, however, we see that the effect of socioeconomic variables is almost fully compensated for by other groups of variables. As Figure 1 illustrates, the similarity of black and white men in emotional support involvement is mostly due to the fact that the effects of SES, culture and extended family characteristics cancel each other. Table 3 shows that income, wealth and education are all linked to higher rates of emotional support provision, and black men have lower SES than white men which discourages emotional support among them and generates a 9.4 percent race gap favoring whites. In contrast, black men have higher levels of extended familistic and altruistic values and higher rates of church attendance than white men, and these cultural characteristics are all positively related to emotional support, generating a 2.85 percent gap 
favoring blacks. Higher rates of coresidence and proximity among blacks also contribute by creating a 2.67 percent black-white gap, and another 1.7 percent can be linked to the contribution of age difference.

Finally, as Figure 1 shows, the similarity of black and white men in

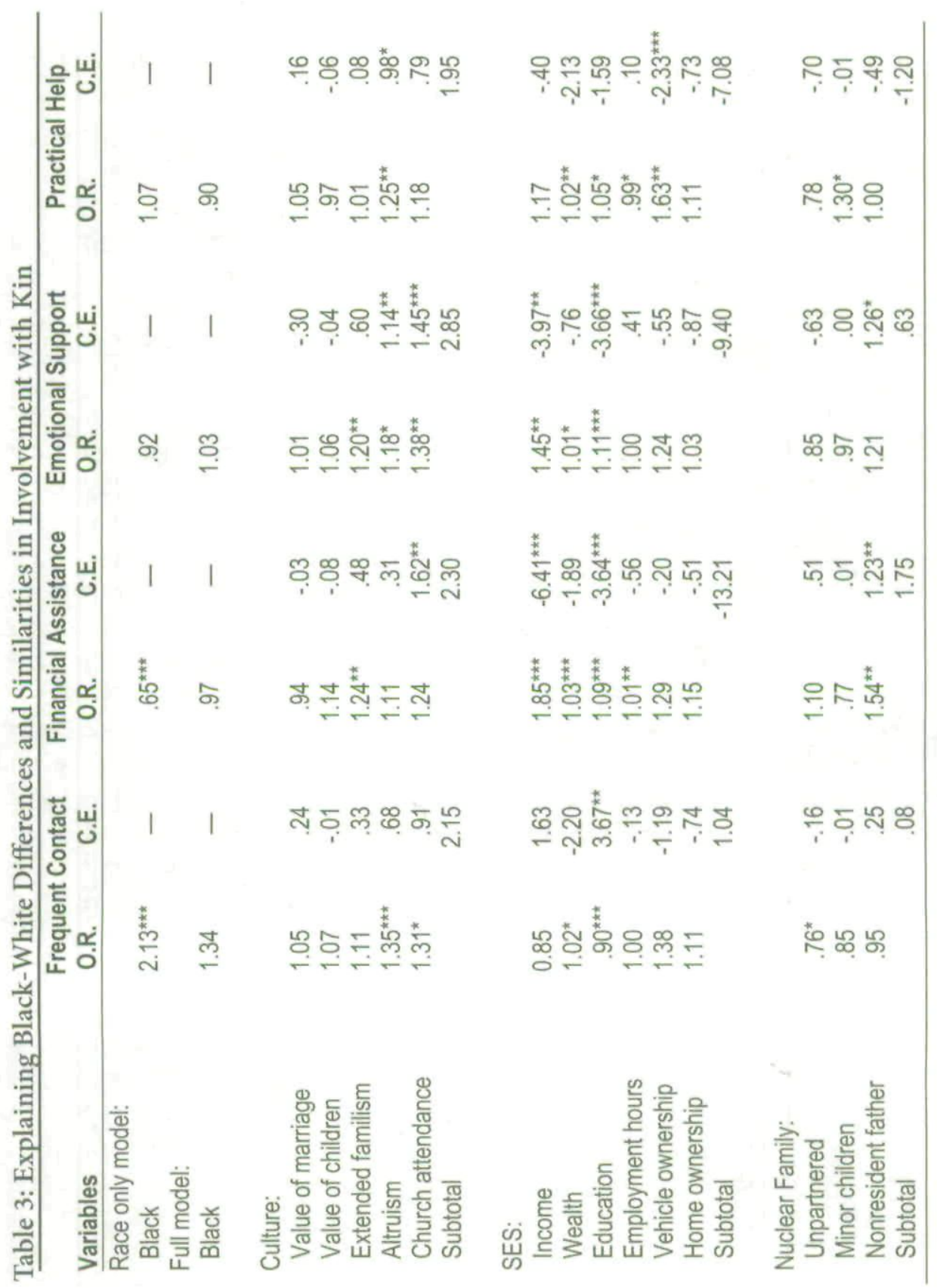


terms of practical help also results from the process wherein the cultural values, extended family characteristics and age counteract the effects of SES. Those with more wealth, with higher levels of education, and vehicle owners are more likely to provide practical help, and these effects generate

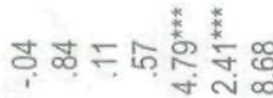

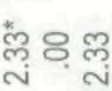

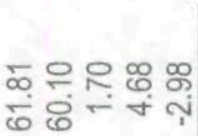

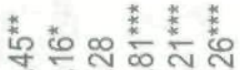

\&ุ ช

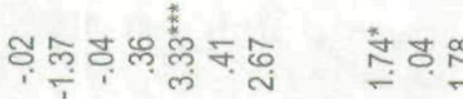

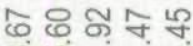
กี่

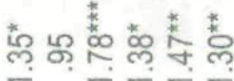

。ั

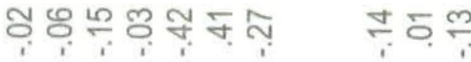

ำลำ 늉

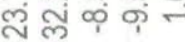

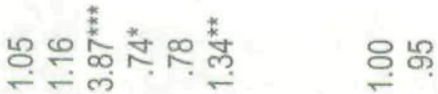

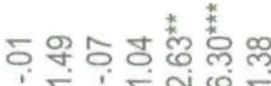

象

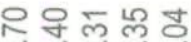

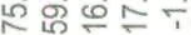

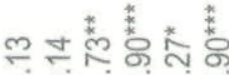

造

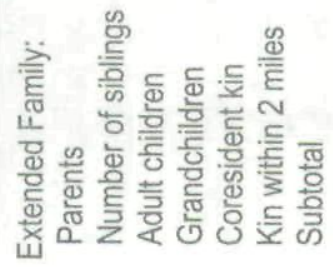

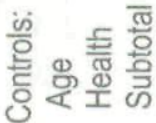

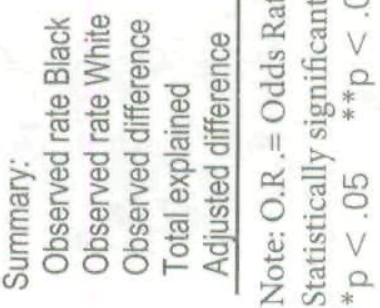


a 7.1 percent gap favoring whites. In contrast, the racial differences in cultural values (especially altruism), the rates of coresidence and living nearby, and the average age more than fully compensate for the effects of SES, producing the observed similarity between blacks and whites.

\section{Discussion}

Overall, two sets of conclusions arise from the analyses presented here: The first addresses the theories about relative levels of family integration among white men and black men, and the second deals with the explanations of racial differences and similarities in family integration.

\section{Disorganization vs. Superorganization Debate}

The data suggest that neither the superorganization nor the disorganization theorists accurately capture the racial distinctions in men's extended family integration. On the one hand, the disorganization theories (Anderson 1990; Wilson 1987) that postulate that black men are especially isolated due to crime, poverty or discrimination, and as a result show a particular propensity to abandon their familial roles, are refuted by the data on extended kin ties. Black men are more likely than white men to live with and near kin, and they are more likely to frequently see their kin in person.

These findings show that despite their lower marriage rates, black men do not necessarily lead lives of social isolation or lack family connections. When talking about families, politicians and social commentators typically focus on the ties between married couples and their children. But this focus on the nuclear family ignores extended family relationships and creates a biased portrait of family life among black men. By taking a broader perspective on family relations and focusing on the often overlooked extended kinship ties, this study refutes the myth that black men lack strong family solidarities.

On the other hand, the proposition of the superorganization theorists, stating in a largely gender-unspecific way that blacks are more involved with their extended families, is also refuted, especially when it comes to the help and support that men provide. In contrast to both of these theoretical approaches, black men are quite similar to white men in their overall levels of kin support involvement, and they are less likely to provide financial assistance.

Note, however, that my measures of kin support focus on noncoresident kin; because blacks are significantly more likely to live with their relatives, the analyses presented here likely understate black men's involvement with their families. Other limitations of the data may lead to 
an overestimate of black kin support. NSFH, like most national datasets, focuses on non-institutionalized population, omitting the incarcerated men, among whom black men are overrepresented. Incarcerated men are likely to have low levels of extended family involvement (Browning, Miller and Spruance 2001), and their omission may lead to an overestimate of kin integration among black men.

Overall, this study demonstrates that the general either/or terms of the disorganization versus superorganization debate are problematic. The findings lend support to the arguments of multiracial feminist scholars who have criticized this debate for its underlying assumption that Black families are either "better" or "worse" organized (Baca Zinn 1994; Collins 2000).

\section{Explanations of Racial Differences and Similarities}

Exploring the factors behind the racial differences and similarities in family integration, this study finds that SES is central to our understanding of extended family integration patterns, but its role is more complex than commonly theorized. On the one hand, the lower SES of black men (as compared to white men) is linked to higher levels of coresidence, living near kin, and frequent face-to-face contact. On the other hand, net of proximate living, black men's economic disadvantage appears to hinder their kin support involvement.

Although a large portion of the race gaps in coresidence and proximate living was explained by SES, these differences were not fully explained. It is possible that, to fully account for such differences, future research should build contextual models that specify the characteristics of respondents' kin or broader communities, such as racial segregation and socioeconomic composition. Remaining differences in family integration may be explained by the availability of material resources, institutions, and even values in particular neighborhoods and communities.

Further, my data indicate that the similarities in kin support provision do not mean that black men are just "being men" when it comes to kin support. In fact, the apparent similarities of black and white men in emotional support and practical help are due to the fact that the effects of SES and the effects of cultural values and extended family structure cancel each other out. Thus, the data refute the irrelevance model of similarity and support the paradox model that suggests that various factors push the race differential in opposite directions. Specifically, on the one hand, black men have lower SES than white men and that discourages kin support of blacks. On the other hand, black men have higher levels of extended familistic and altruistic values and higher rates of coresidence 
and living near kin than white men, all of which boost black men's kin support involvement.

The racial difference in financial help, in contrast, emerges for the most part because one group of factors - socioeconomic characteristics - is key for explaining this type of support. It is clear that black men are more likely to be poor and therefore do not have the financial resources to share with kin. The effect of race differences in SES is too large to be fully compensated for by other factors.

Taken together, these findings suggest that whereas black men's economic disadvantage hinders their kin support, their cultural values and extended family structure tend to bring their involvement with kin to the levels of the more economically advantaged white men. Thus, one set of propositions generated by the culture versus structure debate is clearly refuted: There is no evidence to support the propositions of the cultural deficiency theorists, who claim that deviant black cultural values reduce their familial integration. In contrast, the other three theories find some support. In line with the argument of structural destruction theorists, this study shows that socioeconomic disadvantage translates into disadvantage in familial involvement for black men. But the data also support the argument of cultural resiliency theorists that blacks' cultural values boost their family integration, even though the impact of culture is smaller than that of social class. Furthermore, the data also lend some support to the propositions of structural resiliency theorists, who argue that poverty increases familial integration. Such processes are evident for the two proximity measures, coresidence and living nearby. Furthermore, the effects of proximity also play an important role in compensating for the dampening effects of socioeconomic variables in kin support.

Although structural factors appear more influential than cultural values, both structure and culture are important in understanding black men's familial involvement: Whatever advantages black men have over white men in terms of family integration come from their cultural values and extended family structure; whatever disadvantages they have stem from their socioeconomic position. Therefore, this analysis offers support to those theorists who have argued against the culture versus structure dichotomy (Roschelle 1997; Sewell 1992; Sudarkasa 1996). Indeed, it is important to consider both cultural and structural factors to fully understand the race differences and similarities in family organization.

These findings also have methodological implications, suggesting that explanatory models should be applied not only to group differences but also to group similarities. In this study, the observed similarities were explained using what I termed the paradox model. Specifically, the study demonstrated that different explanatory factors can push the race 
differential in opposite directions, producing the observed similarities. Future sociological research should pay more attention to similarities and avoid the tendency to focus only on differences.

\section{Conclusion}

This study suggests that we need to transcend the binary approach to black families implicit in the disorganization vs. superorganization debate because such an approach misrepresents the reality of family life. Both disorganization and superorganization theories produce overall judgments of black families as either positive, ensuring economic survival and preserving cultural traditions, or negative, hindering economic success and reducing available support and resources.

Both of these alternatives are deeply flawed. The superorganization theorists are critical of the view of black families as disorganized and pathological; therefore, they emphasize only the positive aspects of black family life. This creates a romanticized portrayal of black families. That portrayal has implications not only for sociological analysis of families but also for social policy. It suggests that black families are fully protected by familial support safety nets, in need of neither assistance nor structural changes. The analysis presented here clearly suggests otherwise, demonstrating the dampening effects of economic disadvantage on support networks.

In contrast, disorganization theorists strive to avoid portraying black families as having all the support they need; therefore, they emphasize the social ills of poor black families. As a result, the black family is portrayed as pathological and black men as negligent, blamed for poverty, crime and other social ills plaguing black communities, and deemed undeserving of governmental aid (Baca Zinn 1994). To avoid both of these misrepresentations, future research on black families should strive to explain differences and similarities by carefully examining the interplay of economic conditions and cultural values.

\section{References}

Allen, Richard L., and Richard P. Bagozzi. 2001. "Consequences of the Black Sense of Self." Journal of Black Psychology 27(1):3-28.

Allen, Walter R. 1979. "Class, Culture and Family Organization: The Effects of Class and Race on Family Structure in Urban America." Journal of Comparative Family Studies 10(3):301-13.

Ambert, Anne Marie. 1992. The Effect of Children on Parents. Hawthorne. 
Anderson, Elijah. 1990. Streetwise: Race, Class, and Change in an Urban Community. University of Chicago Press.

Aschenbrenner, Joyce. 1975. Lifelines: Black Families in Chicago. Holt, Rinehart and Winston.

Baca Zinn, Maxine. 1994. "Feminist Rethinking From Racial-Ethnic Families." Pp. 303-14. Women of Color in U.S. Society. M. Baca Zinn and B. Thornton Dill, editors. Temple University Press.

Billingsley, Andrew. 1992. Climbing Jacob's Ladder: The Enduring Legacy of Black Families. Simon \& Schuster.

Browning, Sandra Lee, R. Robin Miller, and Lisa M. Spruance. 2001. "Criminal Incarceration Dividing the Ties That Bind: Black Men and Their Families." Journal of African American Men 6(1):87-102.

Burr, Jeffrey A., and Jan E. Mutchler. 1999. "Race and Ethnic Variation in Norms of Filial Responsibility Among Older Adults." Journal of Marriage and the Family 61(3):674-87.

Carson, Emmett. 1989. "The Evolution of Black Philanthropy." Pp. 92-102. Philanthropic Giving: Studies in Varieties and Goals. R. Magat, editor. Oxford University Press.

Collins, Patricia Hill. 2000. Black Feminist Thought: Knowledge, Consciousness, and the Politics of Empowerment, 2nd Edition. Routledge.

Cooney, Teresa M., and Peter Uhlenberg. 1992. "Support From Parents Over the Life Course: The Adult Child's Perspective." Social Forces 71(1):63-84.

Coward, Raymond T., Gary R. Lee, Julie K. Netzer, Stephen J. Cutler, and Nicholas L. Danigelis, 1996. "Racial Differences in the Household Composition of Elders by Age, Gender, and Area of Residence." International Journal of Aging and Human Development 42(3): 205-27.

Eggebeen, David J. 1992. "Family Structure and Intergenerational Exchange." Research on Aging 14(4):427-47.

Epstein, Cynthia. 1988. Deceptive Distinctions: Sex, Gender and the Social Order. Yale University Press.

Frazier, E. Franklin. 1939. The Negro Family in America. University of Chicago Press.

Gaines, Stanley O., et al. 1997. "Links Between Race/Ethnicity and Cultural Values As Mediated by Racial/Ethnic Identity and Moderated by Gender." Journal of Personality and Social Psychology 72(6):1460-76. 
Gallagher, Sally, and Naomi Gerstel. 2001. "Connections and Constraints: The Effects of Children on Caregiving." Journal of Marriage and Family 63(1):265-75.

Gerstel, Naomi, and Natalia Sarkisian, 2006. "Marriage: The Good, the Bad, and the Greedy." Contexts 5(4):16-21.

. Forthcoming. "The Color of Family Ties: Race, Class, Gender, and Extended Family Involvement." American Families: A Multicultural Reader. Stephanie Coontz, Maya Parson and Gabrielle Rayley, editors. Routledge.

Glick, Jennifer E., Frank D. Bean and Jennifer V. W. Van Hook. 1997. "Immigration and Changing Patterns of Extended Family Household Structure in the United States: 1970-1990." Journal of Marriage and the Family 59(1):177-91.

Goldscheider, Frances K., and Regina M. Bures. 2003. "The Racial Crossover in Family Complexity in the United States." Demography 40(3):569-87.

Hatch, Laurie Russell. 1991. "Informal Support Patterns of Older African-American and White Women: Examining Effects of Family, Paid Work, and Religious Participation." Research on Aging 13(2):144-70.

Hoffman, Lois Wladis, and Jean Denby Manis. 1979. "The Value of Children in the United States: A New Approach to the Study of Fertility." Journal of Marriage and the Family 41(3):583-96.

Hogan, Dennis P., David J. Eggebeen and Clifford C. Clogg. 1993. "The Structure of Intergenerational Exchanges in American Families." American Journal of Sociology 98(6): 1428-58.

Jacobsen, R. Brooke, and Jerry J. Binger. 1991. "Black Versus White Single Parents and the Value of Children." Journal of Black Studies 21(3):302-12.

Jayakody, Rukmalie. 1998. "Race Differences in Intergenerational Financial Assistance: The Needs of Children and the Resources of Parents." Journal of Family Issues 19(5):508-33.

Johnson, Colleen L. 1999. "Family Life of Older Black Men." Journal of Aging Studies 13(2): 145-60.

. 2000. "Perspectives on American Kinship in the Later 1990s." Journal of Marriage and the Family 62(3):623-39.

Johnson, G. David, Marc Matre and Gigi Armbrecht. 1991. "Race and Religiosity: An Empirical Evaluation of a Causal Model." Review of Religious Research 32(3):252-66.

Krause, Neal. 2002. "Exploring Race Differences in a Comprehensive Battery of Church-Based Social Support Measures." Review of Religious Research 44(2):126-49. 
Laditka, James N., and Sarah B. Laditka. 2001. "Adult Children Helping Older Parents: Variations in the Likelihood and Hours by Gender, Race, and Family Role." Research on Aging 23(4):429-56.

Lempert, Lora Bex. 1999. "Other Fathers: An Alternative Perspective on Black Community Caring." Pp. 189-201. The Black Family: Essays and Studies. Robert Staples, editor. Wadsworth.

Littlejohn-Blake, Sheila M., and Carol Anderson Darling. 1993. "Understanding the Strengths of African American Families." Journal of Black Studies 23(4):460-71.

McDonald, Katrina Bell, and Elizabeth M. Armstrong. 2001. "De-Romanticizing Black Intergenerational Support: The Questionable Expectations of Welfare Reform." Journal of Marriage and the Family 63(1):213-23.

Moore, Gwen. 1990. "Structural Determinants of Men's and Women's Personal Networks." American Sociological Review 55(5):726-35.

Moore, Kristin A., and Thomas M. Stief. 1991. "Changes in Marriage and Fertility Behavior: Behavior Versus Attitudes of Young Adults." Youth and Society 22(3):362-86.

Moynihan, Daniel P. 1965. The Negro Family: A Case for National Action. Washington, DC: U.S. Government Printing Office.

Mutran, Elizabeth. 1985. "Intergenerational Family Support Among Blacks and Whites: Response to Culture or to Socio-Economic Differences." Journal of Gerontology 40(3):382-89.

Newman, Katherine S. 1999. No Shame in My Game: The Working Poor in the Inner City. Alfred Knopf and Russell Sage Foundation.

Nobles, Wade W. 1978. "Toward an Empirical and Theoretical Framework for Defining Black Families." Journal of Marriage and the Family 40(4):679-90.

Nunnally, Jum C. 1978. Psychometric Theory. McGraw-Hill.

Oropesa, R.S., and Bridget K. Gorman. 2000. "Ethnicity, Immigration, and Beliefs About Marriage as a "Tie That Binds"." Pp. 188-211. The Ties That Bind: Perspectives on Marriage and Cohabitation. Linda J. Waite, editor. Aldine de Gruyter.

Patterson, Orlando. 1998. Rituals of Blood: Consequences of Slavery in Two American Centuries. Civitas/Counterpoint.

Raley, R. Kelly. 1995. "Black-White Differences in Kin Contact and Exchange Among Never-Married Adults." Journal of Family Issues 16(1):77-103. 
Roschelle, Anne R. 1997. No More Kin: Exploring Race, Class, and Gender in Family Networks. Sage.

Sarkisian, Natalia, and Naomi Gerstel. 2004. "Kin Support Among Blacks and Whites: Race and Family Organization." American Sociological Review 69(6):812-37.

Forthcoming. "Till Marriage Do Us Part: Adult Children's Relationships with Parents." Journal of Marriage and Family.

Scott, Joseph W., and Albert Black. 1999. "Deep Structures of Black Family Life: Female and Male Kin Networks." Pp. 232-40. The Black Family: Essays and Studies. Robert Staples, editor. Wadsworth.

Sewell, William H.J. 1992. "A Theory of Structure: Duality, Agency, and Transformation." American Journal of Sociology 98(1):1-29.

Silverstein, Merril, and Linda J. Waite. 1993. "Are Blacks More Likely Than Whites to Receive and Provide Social Support in Middle and Old Age? Yes, No, and Maybe So." Journal of Gerontology: Social Sciences 48:S212-22.

South, Scott J., and Eric P. Baumer. 2000. "Deciphering Community and Race Effects on Adolescent Premarital Childbearing." Social Forces 78(4):1379-408.

Spitze, Glenna, and Sonia Miner. 1992. "Gender Differences in Adult Child Contact Among Black Elderly Parents." The Gerontologist 32(2):213-18.

Stack, Carol B. 1974. All My Kin: Strategies for Survival in a Black Community. Harper \& Row.

Staples, Robert E. 1981. "The Myth of the Black Matriarchy." Pp. 335-48. The Black Women Cross-Culturally. Filomena Steady Chioma, editor. Schenkmann.

Sudarkasa, Niara. 1988. "Interpreting the Black Heritage in Afro-American Family Organization." Pp. 27-43. Black Families (2nd Edition). Harriette Pipes McAdoo, editor. Sage Publications.

Sweet, James A., and Larry L. Bumpass. 1996. The National Survey of Families and Households - Waves 1 and 2: Data Description and Documentation. http:// www.ssc.wisc.edu/nsfh/home.htm. Madison, WI: University of WisconsinMadison, Center for Demography and Ecology.

Taylor, Robert Joseph, M. Belinda Tucker, Linda M. Chatters and Rukmalie Jayakody. 1997. "Recent Demographic Trends in African American Family Structure." Pp. 14-62. Family Life in Black America. Robert Joseph Taylor and James S. Jackson, editors. Sage.

Taylor, Robert Joseph, Linda M. Chatters, Rukmalie Jayakody, and Jeffrey S. Levin. 1996. "Black and White Differences in Religious Participation: A Multisample Comparison." Journal for the Scientific Study of Religion 35(4):403-10. 
Taylor, Robert Joseph, Linda M. Chatters, M. Belinda Tucker, and Edith Lewis. 1990. "Developments in Research on Black Families: A Decade Review." Journal of Marriage and the Family 52(4):993-1014.

Thompson, Kenrick S. 1980. "A Comparison of Black and White Adolescents' Beliefs About Having Children." Journal of Marriage and the Family 42(1):133-39.

Tucker, Belinda M., and Claudia Mitchell-Kernan. 1995. "Trends in Black Family Formation: A Theoretical and Statistical Overview." Pp. 3-26. The Decline of Marriage Among Blacks: Causes, Consequences, and Policy Implications. Belinda M. Tucker and Claudia Mitchell-Kernan, editors. Russell Sage Foundation.

Tucker, M. Belinda. 2000. "Marital Values and Expectations in Context: Results from a 21-City Survey." Pp. 166-87. The Ties That Bind: Perspectives on Marriage and Cohabitation. Linda J. Waite, editor. Aldine de Gruyter.

Wallerstein, Judith S., and Joan Berlin Kelly. 1980. Surviving the Breakup. Basic Books.

Whitmore, Gerald. 1999. "African American Father Figures and Children's Achievement." Journal of African American Men 4(1):25-35.

Wilson, John, and Marc A. Musick. 1997. "Who Cares? Toward an Integrated Theory of Volunteer Work." American Sociological Review 62(5):694-713.

Wilson, William J. 1987. The Truly Disadvantaged: The Inner City, the Underclass, and Public Policy. University of Chicago Press. 


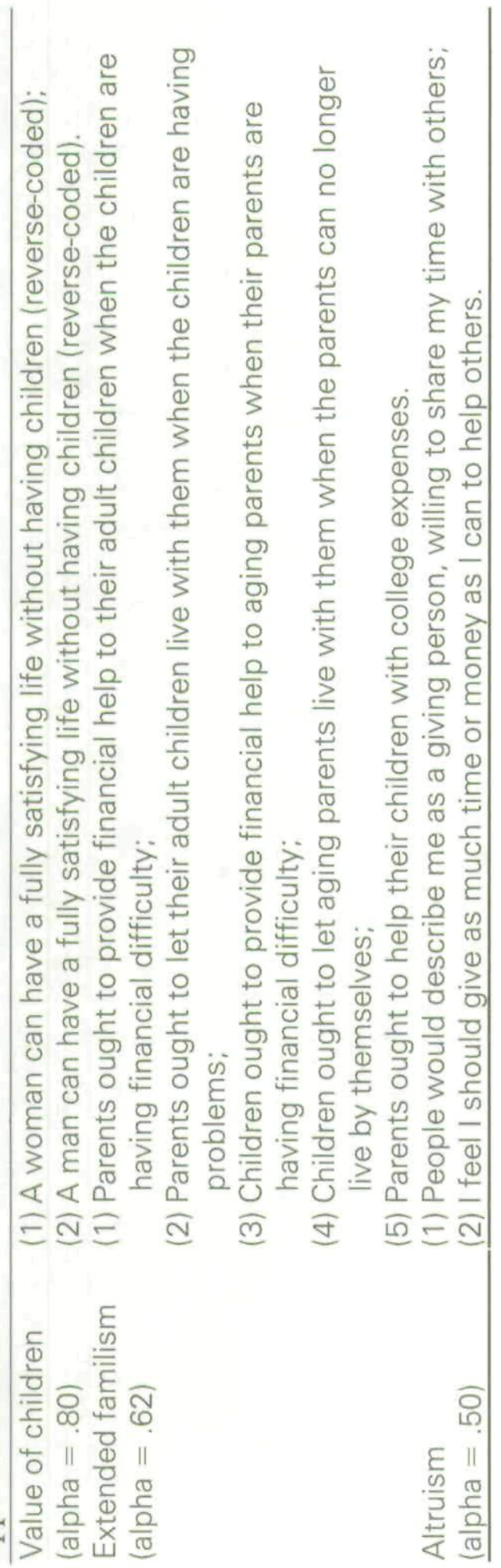


Copyright of Social Forces is the property of University of North Carolina Press and its content may not be copied or emailed to multiple sites or posted to a listserv without the copyright holder's express written permission. However, users may print, download, or email articles for individual use. 